\title{
Investigação do desempenho de blendas PA6/HIPS compatibilizadas com SEBS-MA. Efeito do teor do compatibilizante nas propriedades mecânicas, termomecânicas, reometria de torque e na morfologia
}

\author{
Performance investigation of PA6/HIIPS blends compatibilized with SEBS-MA. Effect of \\ compatibilizer content on mechanical, thermomechanical, torque rheometry and morphology
}

properties

Investigación del rendimiento de mezclas de PA6/HIPS compatibilizadas con SEBS-MA. Efecto del contenido de compatibilizador en las propiedades mecánicas, termomecánicas, reometría de torque y morfología

Jessika Andrade dos Santos Nogueira ORCID: https://orcid.org/0000-0001-7487-8965 Universidade Federal de Campina Grande, Brasil E-mail: jessikandrde@gmail.com

Carlos Bruno Barreto Luna ORCID: https://orcid.org/0000-0002-2441-7439 Universidade Federal de Campina Grande, Brasil E-mail: brunobarretodemaufcg@ hotmail.com

Danilo Diniz Siqueira

ORCID: https://orcid.org/0000-0002-3533-513X Universidade Federal de Campina Grande, Brasil E-mail: danilodinizsiqueira@gmail.com

Edson Antônio dos Santos Filho ORCID: https://orcid.org/0000-0003-4718-8250 Universidade Federal de Campina Grande, Brasil E-mail: edson.a.santos.f@gmail.com

Edcleide Maria Araújo

ORCID: https://orcid.org/0000-0003-4906-864X Universidade Federal de Campina Grande, Brasil E-mail: edcleide.araujo@ufcg.edu.br

\begin{abstract}
Resumo
Blendas de poliamida 6 (PA6) com poliestireno de alto impacto (HIPS) foram preparadas, utilizando-se o copolímero de estireno-(etileno-butileno)-estireno enxertado de anidrido maleico (SEBS-MA), como agente compatibilizante. As blendas foram preparadas em uma extrusora de rosca dupla corrotacional e, posteriormente, moldadas por injeção. As propriedades de reometria de torque, resistência ao impacto Izod, temperatura de deflexão térmica (HDT) e microscopia eletrônica de varredura (MEV) foram investigadas. Os resultados mostraram que houve um aumento no torque das blendas de PA6/HIPS com a adição do compatibilizante SEBS-MA. A resistência ao impacto e a HDT aumentaram $56 \%$ e $24,5 \%$ em comparação com a PA6 pura, quando a formulação da blenda PA6/HIPS contém 15 pcr de SEBS-MA. Essa blenda apresentou uma maior estabilidade na morfologia, conforme verificado no MEV, com melhor adesão interfacial e menor quantidade de vazios, resultando principalmente na maior resistência ao impacto. Em geral, as propriedades de resistência ao impacto e HDT da PA6 podem ser adaptadas e aprimoradas por meio do desenvolvimento de blendas poliméricas.
\end{abstract}

Palavras-chave: Poliamida 6; HIPS; Tenacificação; Compatibilização; Copolímero reativo.

\begin{abstract}
Blends of polyamide 6 (PA6) with high-impact polystyrene (HIPS) were prepared, using maleic anhydride grafted styrene-(ethylene-butylene)-styrene copolymer (SEBS-MA), as a compatibilizer agent. The blends were prepared in a co-rotating twin-screw extruder and subsequently injection molded. The properties of torque rheometry, Izod impact strength, heat deflection temperature (HDT) and scanning electron microscopy (SEM) were investigated. The results showed that there was an increase in the torque of the PA6/HIPS blends with the addition of the SEBS-MA compatibilizer. Impact strength and HDT increased by $56 \%$ and $24.5 \%$ compared to neat PA6 when the PA6/HIPS
\end{abstract}


blended formulation contains 15 pcr of SEBS-MA. This blend showed greater stability in morphology, as verified in the SEM, with better interfacial adhesion and less voids, resulting mainly in greater impact strength. In general, the impact strength and HDT properties of PA6 can be adapted and improved by developing polymer blends.

Keywords: Polyamide 6; HIPS; Toughening; Compatibilization; Reactive copolymer.

\section{Resumen}

Se prepararon mezclas de poliamida 6 (PA6) con poliestireno de alto impacto (HIPS), utilizando anhídrido maleico injertado copolímero de estireno-(etileno-butileno)-estireno (SEBS-MA), como agente compatibilizador. Las mezclas se prepararon en una extrusora de doble tornillo corrotante y posteriormente se moldearon por inyección. Se investigaron las propiedades de reometría de torque, la resistencia al impacto Izod, la temperatura de deflexión térmica (HDT) y la microscopía electrónica de barrido (MEB). Los resultados mostraron que había un aumento en el torque de las mezclas PA6/HIPS con la adición del compatibilizador SEBS-MA. La resistencia al impacto y el HDT aumentaron un $56 \%$ y un $24,5 \%$ en comparación con la PA6 pura cuando la formulación de la mezcla PA6/HIPS contiene 15 pcr de SEBS-MA. Esta mezcla mostró una mayor estabilidad en la morfología, como se verificó en el MEB, con una mejor adhesión interfacial y menos vacíos, lo que se traduce principalmente en una mayor resistencia al impacto. En general, la resistencia al impacto y las propiedades HDT de la PA6 pueden adaptarse y mejorarse mediante el desarrollo de mezclas de polímeros.

Palabras clave: Poliamida 6; HIPS; Tenacificación; Compatibilización; Copolímero reactivo.

\section{Introdução}

As blendas poliméricas podem ser definidas como a mistura física de dois ou mais polímeros, visando alcançar um produto final cujas propriedades atendam aos requisitos técnicos para uma determinada aplicação (Silva et al., 2014; Luna et al., 2014; Luna et al., 2015; Idumah, 2021). A produção de misturas poliméricas é uma das estratégias tecnológicas para o desenvolvimento de novos materiais, com propriedades diferenciadas e aprimoradas em comparação aos polímeros puros, além de apresentar baixo custo, quando comparado à síntese de novos polímeros (Agrawal et al., 2008a; Bezerra et al., 2014; Luna et al., 2015b). Em geral, as blendas poliméricas têm sido extensivamente fabricadas para melhorar a performance de plásticos de engenharia sensíveis ao entalhe, ou seja, promover o processo de tenacificação (Wang et al., 2006; Xu et al., 2020). Devido a importância tecnológica e industrial, a poliamida 6 (Nylon) é bastante investigada para o desenvolvimento de blendas reativas de alto desempenho (Wang et al., 2021; Wei et al., 2021; Luna et al., 2021).

A PA6 tem boa resistência química, baixa viscosidade no estado fundido, boa resistência à abrasão, boas propriedades mecânicas e térmicas e, por isso, está inserida na classe dos plásticos de engenharia (Araújo et al., 2003a). Todavia, a sua sensibilidade à propagação de trinca quando entalhada, alta absorção de umidade e baixa temperatura de deflexão térmica (HDT) comprometem o seu uso em algumas aplicações (Correa et al., 2007). Para contornar essas deficiências inerentes da PA6, em geral, a indústria e as pesquisas acadêmicas sugerem o desenvolvimento e processamento de misturas com outros polímeros, como o acrilonitrilo-butadieno-estireno (ABS) (Araújo et al., 2004), a acrilonitrila-EPDM-Estireno (AES) (Bassani et al., 2005), o etileno-propileno-dieno (EPDM) (Barra et al., 2003), o estireno-etileno-butileno-estireno (SEBS) (Carvalho e Sirqueira (2016)) e o polietileno-1-octeno (POE) (Bo et al., 2021). Esses polímeros misturados diretamente em uma matriz de PA6 não produzirão materiais com altas propriedades mecânicas, devido a presença de grupos funcionais $\left(\mathrm{NH}_{2}, \mathrm{COOH}\right.$ e CONH) na cadeia da PA6. Em vista disso, os agentes de compatibilização funcionalizados com anidrido maleico têm sido bastante efetivos, já que os grupos anidridos são capazes de reagir com os grupos funcionais da PA6 (Agrawal et al., 2009).

A eficácia do estireno-acrilonitrila-anidrido maleico (SAN-MA), contendo 7\% de MA, foi avaliada na compatibilização da blenda PA6/ABS por Ren et al. (2008). As blendas foram processadas em uma extrusora e, posteriormente, moldadas por injeção. Ocorreu uma diminuição na tensão de escoamento e na resistência à flexão com a adição de SAN-MA, porém a resistência ao impacto aumentou em comparação com a PA6 pura. Com o aumento do teor de SAN-MA, a resistência ao impacto, à tensão no escoamento e o alongamento na ruptura aumentaram. A blenda PA6/ABS/SAN-MA (80/20/4pcr) apresentou o melhor equilíbrio de propriedades, chegando a um aumento de oito vezes na resistência ao impacto, em relação a PA6. As morfologias obtidas por MEV demonstraram que, com a adição de SAN-MA, o 
ABS apresentou um refinamento e uma melhor dispersão, bem como mostrou boa adesão interfacial nas misturas PA6/ABS.

Oliveira et al. (2017) investigaram a influência do teor de anidrido maleico (3, 5 e 10\% de MA), nas propriedades mecânicas, termomecânicas e na morfologia do sistema PA6/AES/MMA-MA (66,5/28,5/5 \% em massa). Verificou-se que a incorporação do compatibilizante metacrilato de metila-anidrido maleico (MMA-MA) na blenda PA6/AES melhorou as propriedades mecânicas de resistência ao impacto, módulo elástico e alongamento na ruptura. As blendas PA6/AES/MMAMA contendo 3 e 5\% de MA exibiram morfologias e propriedades mecânicas semelhantes. Quando a blenda PA6/AES/MMAMA foi compatibilizada com um teor de $10 \%$ de MA, observou-se uma redução nas propriedades mecânicas, em relação às demais blendas compatibilizadas. Esse comportamento foi atribuído ao excesso de MA que não reagiu durante o processamento. A adição de AES aumentou drasticamente a temperatura de deflexão térmica (HDT) do sistema PA6/AES, em comparação com a poliamida pura. O aumento na estabilidade termomecânica foi atribuído à presença da fase SAN. A incorporação de MMA-MA provocou uma nova redução nos valores de HDT, em comparação com a blenda PA6/AES. Essa propriedade não foi afetada com o aumento do teor de MA, somente ocorreu uma manutenção dos valores.

Luna et al. (2020a) investigaram blendas de poliamida 6 (PA6)/copolímero de etileno-propileno-dieno enxertado com anidrido maleico (EPDM-MA), contendo $1 \%$ de anidrido maleico. As blendas foram preparadas em uma extrusora de rosca dupla corrotacional e, posteriormente, os grânulos extrudados foram moldados por injeção. Os resultados mostraram que houve um aumento no torque das blendas PA6/EPDM-MA, em comparação com a PA6. As blendas apresentaram um decréscimo não drástico na resistência à tração, no módulo elástico e na HDT, em relação à PA6. Todavia, ganhos expressivos foram observados no alongamento na ruptura e na resistência ao impacto. A introdução do EPDM-MA na PA6 não afetou os parâmetros de fusão e de cristalização. O ângulo de contato de todas as blendas aumentou em relação à PA6, sugerindo que as misturas são mais hidrofóbicas. Resultados otimizados foram obtidos para a composição contendo 10\% de EPDM-MA, alcançando ganhos de 850 e $213 \%$ na resistência ao impacto e no alongamento na ruptura, respectivamente. A morfologia ilustrou partículas na faixa de 0,1 a $2 \mu \mathrm{m}$, bem dispersas e adequadamente distribuídas na matriz de PA6. Além disso, ao utilizar 10; 12,5 e 15\% de EPDM-MA, a morfologia apresentou um alto nível de deformação plástica, justificando assim os resultados expressivos da resistência ao impacto e do alongamento na ruptura dessas blendas.

Bo et al. (2021) desenvolveram blendas de poliamida 6/ polietileno-1-octeno compatibilizadas com polietileno-1octeno enxertado por anidrido maleico (POE-g-MA), em uma extrusora de dupla rosca. Os autores observaram um aumento de mais de 10 vezes da resistência ao impacto à temperatura ambiente e, ao mesmo tempo, não houve grandes perdas das propriedades de tração, sugerindo um equilíbrio de propriedades.

$\mathrm{Na}$ literatura científica de polímeros praticamente não se localizou trabalhos referentes as blendas de poliamida 6 com o poliestireno de alto impacto (HIPS), configurando um ponto relevante para ser investigado e contribuir para o aumento do banco de dados científicos das blendas poliméricas. Portanto, este trabalho teve como objetivo desenvolver blendas de poliamida 6 (PA6)/poliestireno de alto impacto (HIPS), utilizando o copolímero de estireno-(etileno-butileno)-estireno enxertado com anidrido maleico (SEBS-MA), como agente compatibilizante.

\section{Metodologia}

\section{Materiais}

A poliamida 6 (PA6) foi utilizada como matriz polimérica, comercializada com o código B300®, densidade de 1,13 $\mathrm{g} / \mathrm{cm}^{3}$ e índice de fluidez de $2,9 \mathrm{~g} / 10 \mathrm{~min}\left(235^{\circ} \mathrm{C} / 2,16 \mathrm{~kg}\right)$, na forma de grânulos e fornecida pela Polyform.

O poliestireno de alto impacto (HIPS) foi utilizado como fase dispersa, comercializado com o Styron $478 \circledast$, densidade de $1,05 \mathrm{~g} / \mathrm{cm}^{3}$ e índice de fluidez de 2,9 g/10 $\min \left(200^{\circ} \mathrm{C} / 5 \mathrm{~kg}\right)$, na forma de grânulos e fornecido pela Unigel Química. S.A.

O copolímero estireno-(etileno-butileno)-estireno enxertado com anidrido maleico (SEBS-MA) foi utilizado como 
compatibilizante, sob código comercial FG1901, contendo 1,7\% de anidrido maleico, índice de fluidez de $5 \mathrm{~g} / 10$ min, na forma de grânulos e adquirido da Kraton Polymers do Brasil.

\section{Métodos}

Antes da preparação das blendas, a poliamida 6 (PA6) foi submetida à secagem em estufa sob vácuo, a $80{ }^{\circ} \mathrm{C}$, durante 24 horas. O HIPS e o SEBS-MA foram secos em uma estufa com vácuo durante $24 \mathrm{~h}$, em temperatura de $60^{\circ} \mathrm{C}$. As composiç̃̃es das blendas PA6/HIPS e PA6/HIPS/SEBS-MA são apresentadas na Tabela 1, com as proporções em massa (\%).

Tabela 1. Composições formuladas para produção das blendas PP/HIPS e PP/HIPS/SEBS-MA.

\begin{tabular}{l|c|c|c}
\hline \multicolumn{1}{c|}{ Amostras } & PA6 (\% em massa) & HIPS (\% massa) & SEBS-MA (pcr) \\
\hline PA6 & 100 & - & - \\
PA6/HIPS & 60 & 40 & 5 \\
PA6/HIPS/SEBS-MA & 60 & 40 & 7,5 \\
PA6/HIPS/SEBS-MA & 60 & 40 & 10 \\
PA6/HIPS/SEBS-MA & 60 & 40 & 12,5 \\
PA6/HIPS/SEBS-MA & 60 & 40 & 15 \\
PA6/HIPS/SEBS-MA & 60 & 40 & - \\
HIPS & - & 100 & - \\
\hline
\end{tabular}

Fonte: Dados da pesquisa.

As blendas PP/HIPS e PP/HIPS/SEBS-MA foram misturadas a seco e, posteriormente, processadas em uma extrusora de rosca dupla corrotacional modular, modelo ZSK ( $\mathrm{D}=18 \mathrm{~mm}$ e L/D $=40)$, da Coperion Werner e Pfleiderer. O perfil de temperatura utilizado na extrusora foi de $230^{\circ} \mathrm{C}-230^{\circ} \mathrm{C}-230^{\circ} \mathrm{C}-230^{\circ} \mathrm{C}-230^{\circ} \mathrm{C}-230^{\circ} \mathrm{C}-230^{\circ} \mathrm{C}$, velocidade de rotação da rosca de $250 \mathrm{rpm}$ e taxa de alimentação controlada de $2 \mathrm{~kg} / \mathrm{h}$, com perfil de rosca configurado com elementos de misturas distributivos e dispersivos, conforme a Figura 1. Subsequentemente, as blendas foram granuladas e secas em uma estufa com vácuo durante $24 \mathrm{~h}$, com temperatura de $80^{\circ} \mathrm{C}$. Os polímeros puros (HIPS e à PA6) foram processados e secos nas mesmas condições das blendas para efeito comparativo.

Figura 1. Perfil da rosca da extrusora configurada com elementos de misturas distributivos e dispersivos.

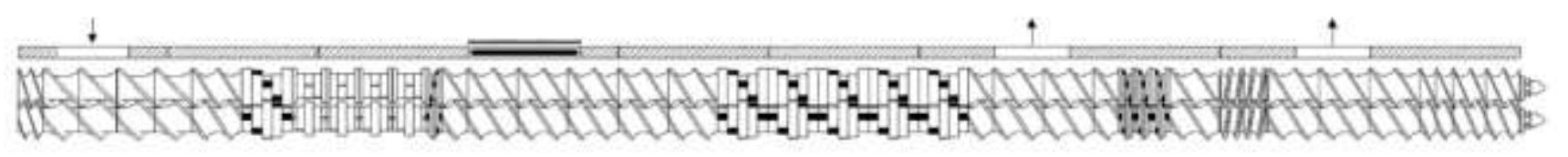

Fonte: Luna et al. (2020b).

Os materiais foram moldados por injeção, em uma injetora Arburg, Modelo Allrounder 207C Golden Edition, para a obtenção de corpos de prova de impacto e HDT, segundo as normas ASTM D256 e ASTM D648, respectivamente. As condições de moldagem dos corpos de prova são apresentadas na Tabela 2. Os corpos de prova foram armazenados em um dessecador com sílica até o momento das caracterizações. 
Tabela 2. Condições de moldagem por injeção dos corpos de prova.

\begin{tabular}{c|c}
\hline Parâmetros & Condições \\
\hline Pressão de injeção (bar) & 1000 \\
Perfil de temperatura $\left({ }^{\circ} \mathrm{C}\right)$ & $230,240,240,240,245$ \\
Temperatura do molde $\left({ }^{\circ} \mathrm{C}\right)$ & 50 \\
Tempo de resfriamento no molde (s) & 30 \\
Pressão de recalque (bar) & 800 \\
\hline
\end{tabular}

Fonte: Dados da pesquisa.

\section{Caracterização dos Materiais}

As curvas reológicas foram obtidas em um misturador Haake PolyLab QC da Thermo Scientific, com rotores do tipo roller, a $230^{\circ} \mathrm{C}$, velocidade de rotação dos rotores de $60 \mathrm{rpm}$, sob atmosfera de ar durante $10 \mathrm{~min}$. A massa total dentro da câmara de mistura foi calculada conforme a Equação 1:

$\mathrm{M}_{\mathrm{t}}=0,7 \times \rho \times \mathrm{V}_{\mathrm{n}}$

Onde: $\rho=$ densidade do material processado; $0,7=$ fator que corresponde a $70 \%$ do volume ocupado na câmera; $\mathrm{V}_{\mathrm{n}}=$ volume livre da câmera de mistura $\left(310 \mathrm{~cm}^{3}\right)$.

O ensaio de resistência ao impacto Izod foi realizado em corpos de prova entalhados, segundo a norma ASTM D256, em um aparelho da marca Ceast modelo Resil 5,5 J, operando com martelo de 2,75 J, em temperatura ambiente $\left(\sim 23{ }^{\circ} \mathrm{C}\right)$. Os resultados foram analisados com uma média de sete corpos de prova.

A temperatura de deflexão térmica (HDT) foi obtida conforme a norma ASTM D648, em um equipamento Ceast, modelo HDT 6 VICAT, com uma tensão de $1,82 \mathrm{MPa}$ e taxa de aquecimento de $120^{\circ} \mathrm{C} / \mathrm{h}$. A temperatura foi determinada após a amostra ser defletida $0,25 \mathrm{~mm}$. Os resultados foram analisados com uma média de três corpos de prova.

As análises por microscopia eletrônica de varredura (MEV) foram realizadas na superfície de fratura dos corpos de prova submetidos ao ensaio de impacto. Utilizou-se um microscópio eletrônico de varredura, VEGAN 3 TESCAN, a uma voltagem de $30 \mathrm{kV}$, sob alto vácuo. As superfícies de fratura das amostras foram revestidas com ouro.

\section{Resultados e Discussão}

\section{Reometria de Torque}

O ensaio de reometria de torque é empregado para avaliar reatividade e a processabilidade de misturas poliméricas. Em geral, o torque é diretamente proporcional à viscosidade e, consequentemente, aumentos nos valores de torque podem ser interpretados como existência de interações entre grupos químicos (Bezera et al., 2017; Lima et al., 2016; Luna et al., 2020c). A Figura 2 ilustra as curvas de torque versus tempo da PA6 pura, do HIPS, do SEBS-MA e das blendas, em função da concentração do compatibilizante. 
Figura 2. Curvas de torque em função do tempo de processamento para à PA6, o HIPS, o SEBS-MA e as blendas, em função do teor de SEBS-MA.

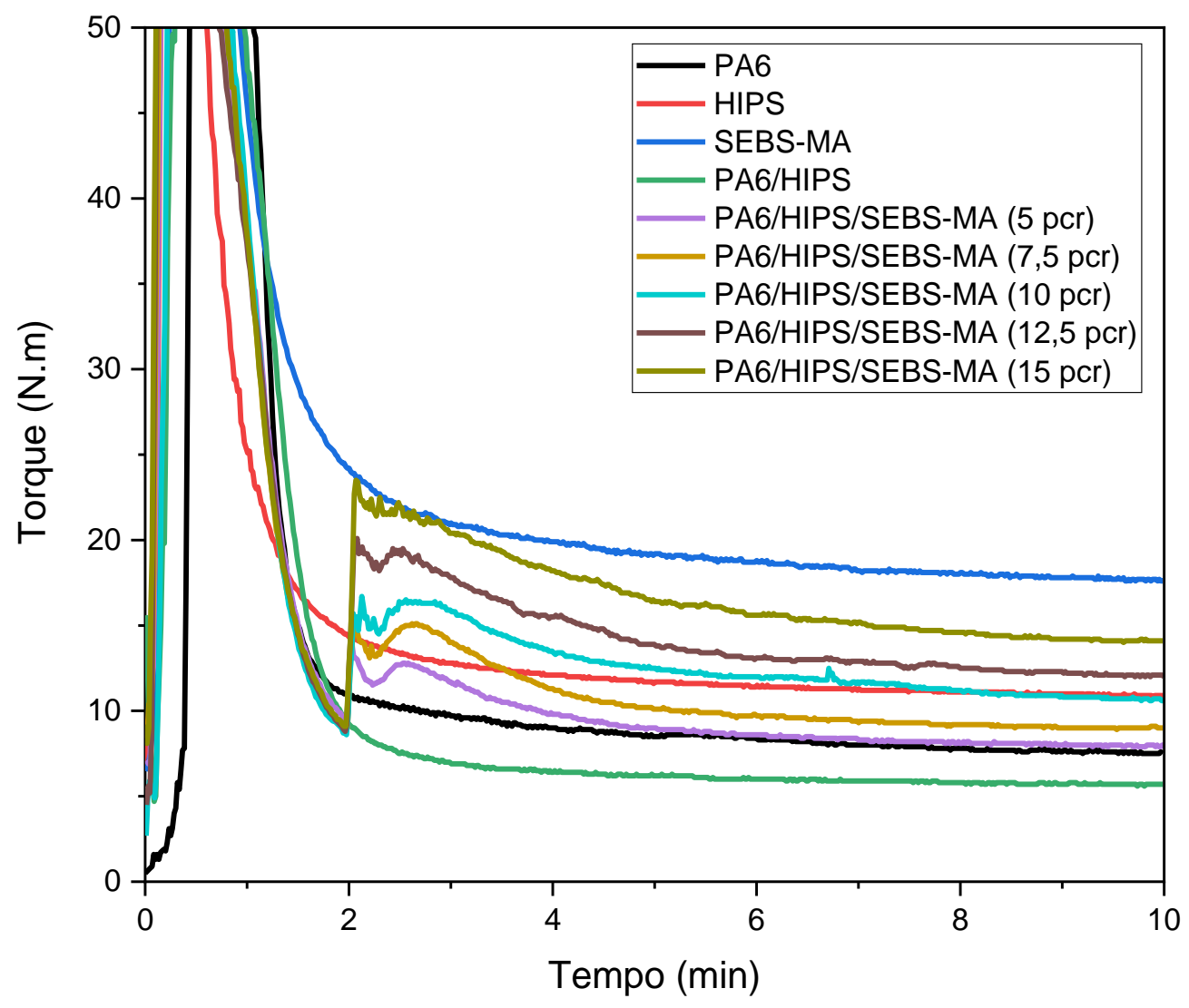

Fonte: Dados da pesquisa.

O HIPS e a PA6 pura apresentaram torques na ordem de 10,9 e 7,5 N.m ao término dos 10 min de processamento, respectivamente. O maior torque foi alcançado pelo compatibilizante SEBS-MA, com valor de 17,6 N.m. Como o torque é diretamente associado a viscosidade, o SEBS-MA apresentou a maior viscosidade nas condições utilizadas de processamento. A mistura direta de PA6/HIPS gerou o menor valor de torque entre todos os materiais, sugerindo uma imiscibilidade. Esse comportamento é atribuído a diferença estrutural entre a PA6 e o HIPS e, portanto, não contribuindo para a formação de interações.

No preparo das blendas PA6/HIPS/SEBS-MA, o compatibilizante SEBS-MA foi adicionado à câmara de mistura em 2 minutos de processo, quando o sistema PA6/HIPS já se encontrava no estado fundido. À medida que aumentou o teor de SEBS-MA nas blendas PA6/HIPS/SEBS-MA, o torque sofreu acréscimo em comparação ao da PA6 pura e a blenda PA6/HIPS, sendo mais pronunciado com 15 pcr de compatibilizante. Quando as blendas são formuladas com 12,5 e 15 pcr de SEBS-MA, o torque superou o do HIPS puro. Como consequência, as blendas compatibilizadas com SEBS-MA aumentaram a viscosidade, indicando um maior nível de interação. Diante disso, o aumento da viscosidade nas blendas PA6/HIPS/SEBS-MA pode ser devido a dois fatores: maior viscosidade do SEBS-MA em relação a PA6 e o HIPS ou formação de interações entre os componentes da mistura. A literatura (Wilkinson et al., 1999; Agrawal et al. 2008; Luna et al., 2020a) tem mostrado que os grupos anidrido maleico do copolímero reativo reagem com os grupos terminais amina da PA6, formando um grupo imida e resultando em um copolímero in situ na interface. Além disso, o sistema PA6/HIPS/SEBS-MA tem a miscibilidade da molécula de estireno do HIPS e do SEBS-MA. A Figura 3 ilustra um esquema hipotético para a interação da blenda PA6/HIPS/SEBS-MA. 
Figura 3. Reação do grupo anidrido do SEBS-MA com a amina da PA6, formando uma imida.

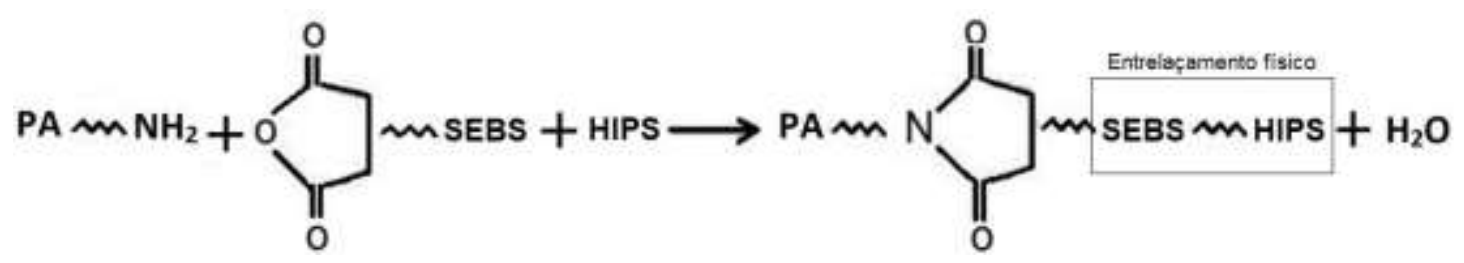

Fonte: Adaptado de Carvalho e Sirqueira (2016).

\section{Microscopia Eletrônica de Varredura (MEV)}

A Figura 4 ilustra a morfologia das blendas de PA6/HIPS e PA6/HIPS/SEBS-MA, com ampliações de 500x e 3000x. A morfologia das blendas PA6/HIPS e PA6/HIPS/SEBS-MA, independentemente do teor de SEBS-MA, é típica de misturas imiscíveis, uma vez que apresentam separação de fases. Todas as blendas apresentam morfologia heterogênea, onde partículas de HIPS encontram-se dispersas na matriz de PA6. Observa-se que, a blenda PA6/HIPS não tem uma boa adesão entre as fases, tendo em vista a grande quantidade de vazios, sugerindo que partículas de HIPS foram arrancadas da superfície durante o teste de impacto. É possível ainda observar a presença de interfaces sem nenhum tipo de adesão e, ao mesmo tempo, partículas com superfícies lisas sem qualquer aspereza, indicando má adesão interfacial. Esta morfologia da blenda PA6/HIPS impacta para deteriorar as propriedades mecânicas, especialmente a resistência ao impacto, como verificado mais adiante na Figura 5. A compatibilização da blenda PA6/HIPS com 5, 7,5 e 10 pcr de SEBS-MA não promoveu uma estabilização total da morfologia, uma vez que ainda se constatam vários vazios e heterogeneidade no tamanho das partículas da fase dispersa (HIPS). Contudo, mesmo que de maneira discreta, já é perceptível algumas partículas dispersas refinadas, as quais podem ser do HIPS ou do SEBS-MA. Como consequência, a resistência ao impacto aumentou de maneira sutil. A adição de 12,5 pcr do compatibilizante SEBS-MA reduziu a quantidade de buracos, sugerindo que aumentou a adesão interfacial entre o HIPS e a PA6. Além disso, verifica-se uma morfologia com maior quantidade de partículas refinadas e, ao mesmo tempo, partículas grandes, sugerindo que ainda tem o processo de coalescência (Sundararaj e Macosko, 1995). A blenda PA6/HIPS/SEBS-MA (15 pcr) apresentou uma morfologia mais estável e refinada, com melhora na adesão entre as fases de PA6 e HIPS, além de uma redução no tamanho médio das partículas, levando a um aumento na resistência ao impacto. 
Research, Society and Development, v. 10, n. 8, e58510817649, 2021

(CC BY 4.0) | ISSN 2525-3409 | DOI: http://dx.doi.org/10.33448/rsd-v10i8.17649

Figura 4. Micrografias das blendas PA6/HIPS e PA6/HIPS/SEBS-MA, em função da concentração de SEBS-MA.

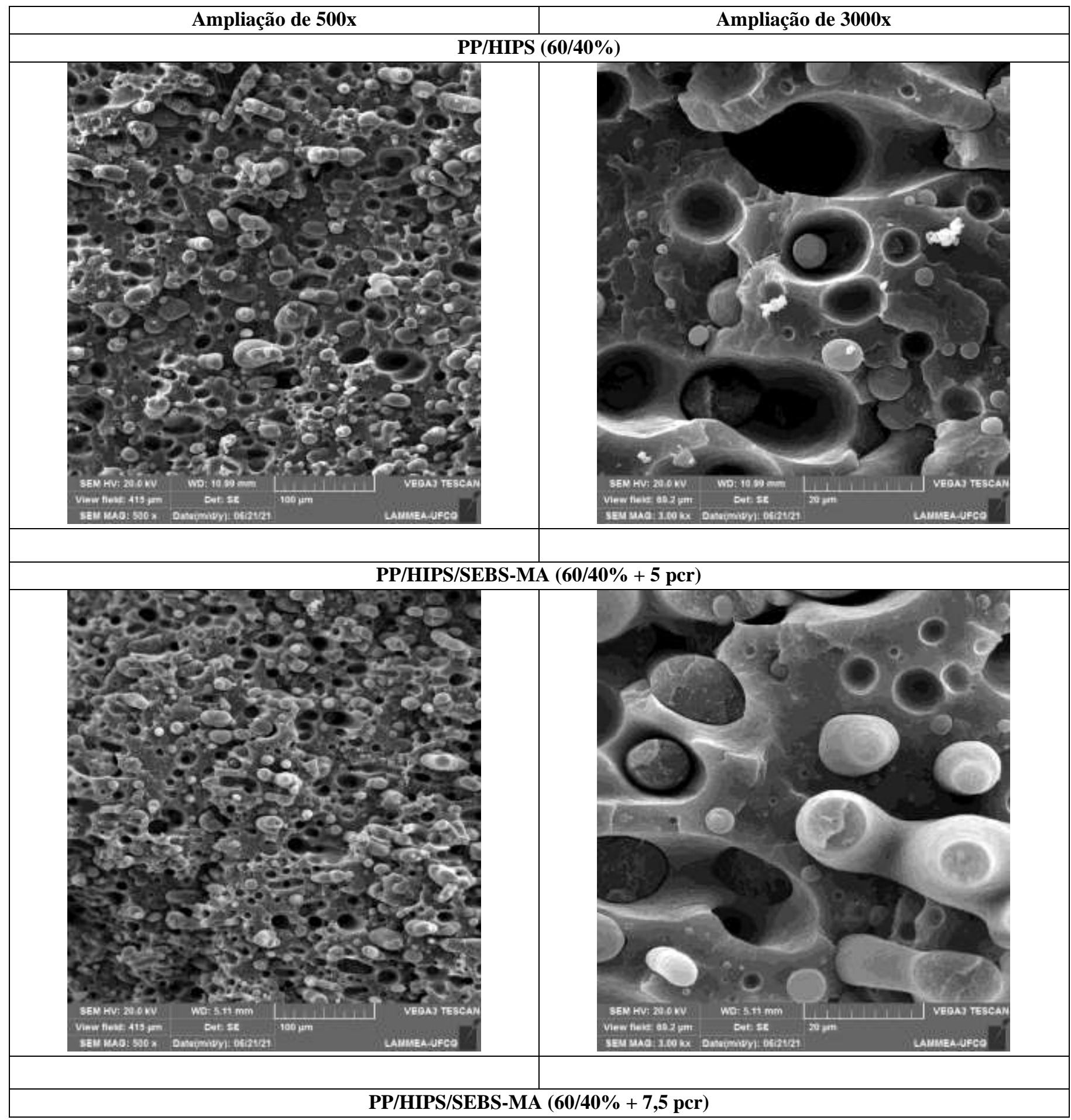


Research, Society and Development, v. 10, n. 8, e58510817649, 2021

(CC BY 4.0) | ISSN 2525-3409 | DOI: http://dx.doi.org/10.33448/rsd-v10i8.17649

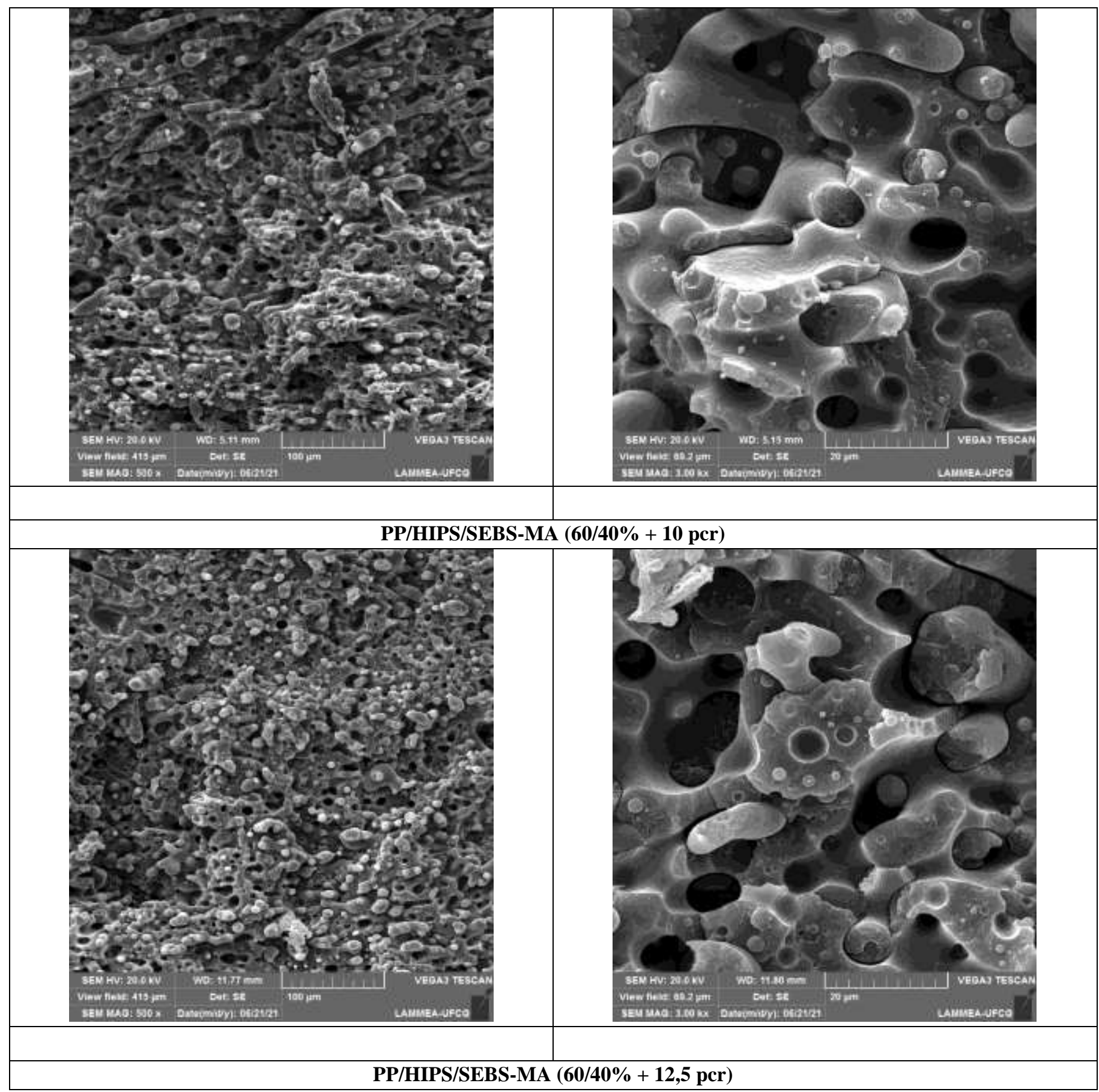


Research, Society and Development, v. 10, n. 8, e58510817649, 2021

(CC BY 4.0) | ISSN 2525-3409 | DOI: http://dx.doi.org/10.33448/rsd-v10i8.17649

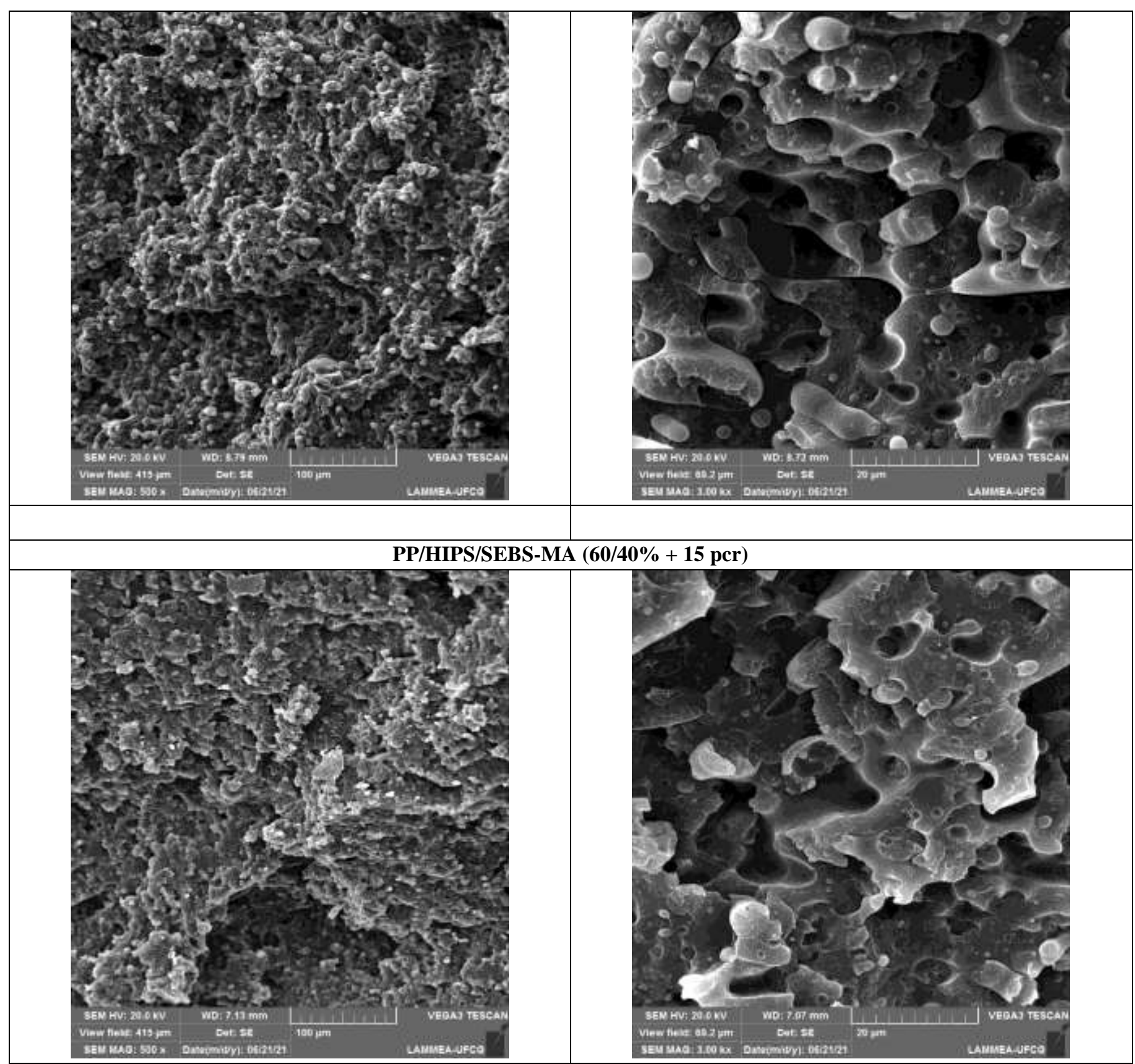

Fonte: Dados da pesquisa.

\section{Resistência ao impacto Izod}

A Figura 5 apresenta os resultados da resistência ao impacto da PA6, do HIPS e das blendas, em função da concentração de SEBS-MA. A PA6 e o HIPS apresentaram resistência ao impacto na ordem de 74,5 J/m e 70 J/m, respectivamente. A adição de 40\% de HIPS na blenda PA6/HIPS provocou uma redução de $12 \%$ na resistência ao impacto, em comparação com a PA6 pura. Isso é devido a diferença de polaridade entre a PA6 e o HIPS (Luna et al., 2015a; Huang et al., 2018), gerando uma baixa interação interfacial e provocando baixa adesão entre as fases, como verificado no MEV. Este comportamento foi também relatado por Tan et al. (2018) nos estudos de blendas de PA6 com poliestireno. As blendas PP/HIPS compatibilizadas com 5 e 7,5 pcr de SEBS-MA aumentaram de forma discreta a resistência ao impacto, em relação ao sistema PP/HIPS sem compatibilizante, com ganhos de 5,8 e 10,8\%, respectivamente. Não é observado nenhum efeito tenacificante significativo com a adição de 5 e 7,5 pcr de SEBS-MA, tendo em vista que os valores de resistência ao impacto são próximos da PA6 pura. 
Observou-se que, a partir de 10 pcr do compatibilizante SEBS-MA na blenda PA6/HIPS, há uma maior tendência de aumentar a resistência ao impacto, corroborando com o comportamento da reometria de torque. A adição de 10 e 12,5 pcr de SEBS-MA na blenda PA6/HIPS melhorou a resistência ao impacto, uma vez que aumentaram seus valores em relação à blenda sem agente compatibilizante. Em adição, essas blendas apresentaram ganhos na resistência ao impacto de 14,2 e 22,5\% em comparação com a PA6 pura, sugerindo que o compatibilizante SEBS-MA promoveu interações entre as fases presentes (Araújo et al., 2003b; Bassani et al., 2002; Esmizadeh et al., 2021). As reações químicas envolvidas na blenda PA6/HIPS/SEBS-MA envolvem os grupos anidrido maleico do compatibilizante SEBS-MA e os grupos terminais amina da PA6 (Agrawal et al., 2010; Chiang e Chang, 1997; Oliveira et al., 2011) e, ao mesmo tempo, há uma miscibilidade parcial entre o poliestireno presente no HIPS e no SEBS-MA. Em termos comparativos para as blendas PA6/HIPS/SEBS-MA, as concentrações 10 e 12,5 pcr de SEBS-MA proporcionam aumentos semelhantes entre si na resistência ao impacto, uma vez que estão dentro do erro experimental.

Figura 5. Resistência ao impacto da PA6 pura, do HIPS e das blendas PP/HIPS, em função do teor de SEBS-MA.

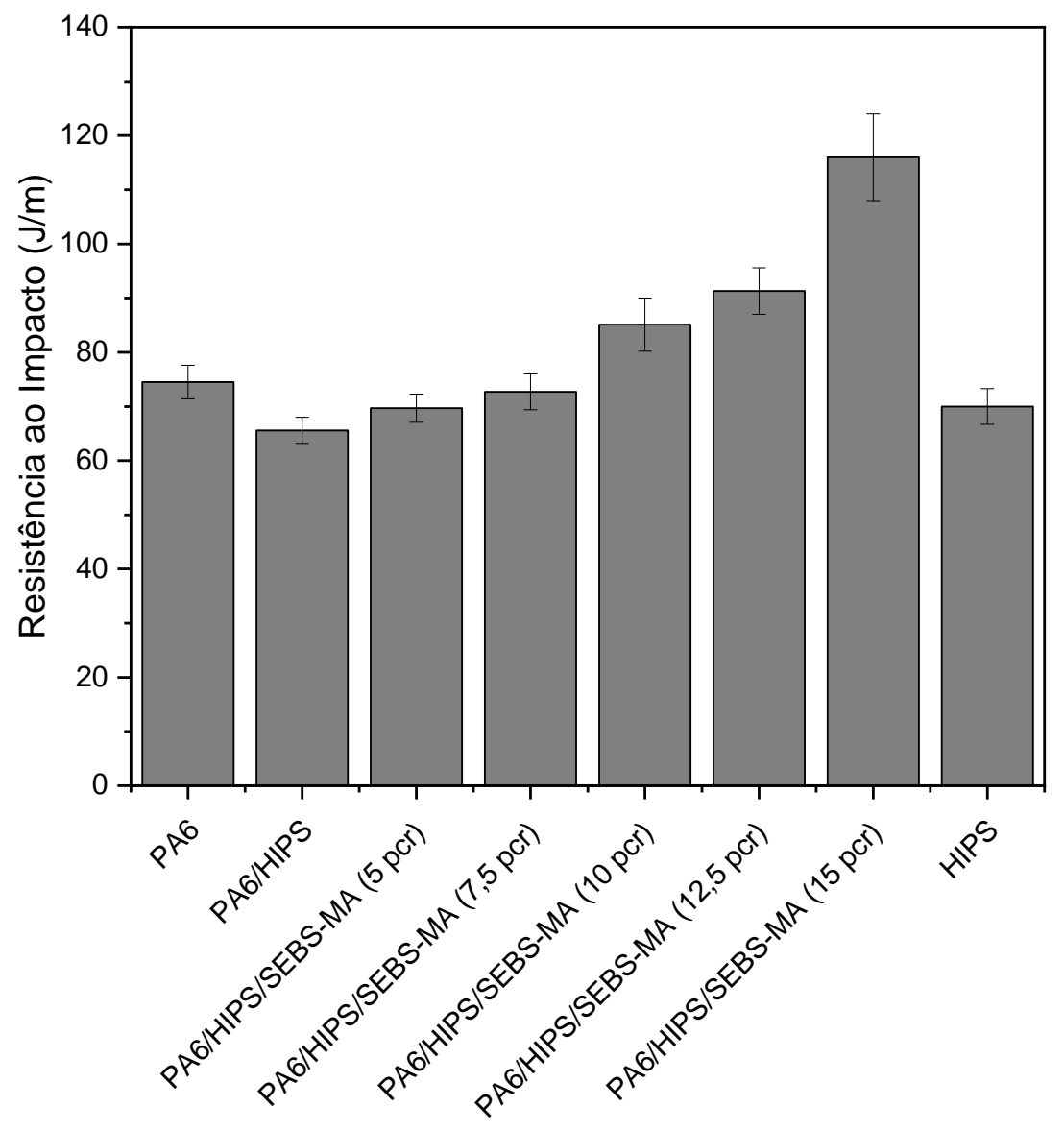

Fonte: Dados da pesquisa.

A tenacificação da PA6 só é atingida por meio de altas concentrações de SEBS-MA. A composição com 15 pcr de SEBS-MA apresentou um aumento mais acentuado da resistência ao impacto, superando a matriz de PA6 em 56\%. Aparentemente, o fator determinante no melhor desempenho da blenda PA6/HIPS/SEBS-MA (15 pcr) quanto à resistência ao impacto é a sua maior concentração de SEBS-MA, impactando para proporcionar uma maior estabilidade na morfologia, como verificado no MEV. Todavia, como a concentração de 15 pcr do SEBS-MA é mais alta, possivelmente parte do compatibilizante ficou disperso na matriz de PA6 e, por consequência, auxiliou no processo de tenacificação (Luna et al., 
2019a; Mello et al., 2018).

\section{Temperatura de Deflexão Térmica (HDT)}

A estabilidade estrutural dos polímeros em temperaturas superiores a ambiente $\left(25^{\circ} \mathrm{C}\right)$ pode ser mensurada por meio da temperatura de deflexão térmica (HDT) (Filho et al., 2020; Luna et al., 2019b). Essa é uma propriedade de grande importância na indústria de transformação, tendo em vista que estabelece a máxima resistência termomecânica dos polímeros (Rusayyis et al., 2018; Luna et al., 2019c). A Figura 6 mostra os resultados da temperatura de deflexão térmica (HDT) da PA6, do HIPS e das blendas, com os diferentes teores do compatibilizante SEBS-MA.

Figura 6. Comportamento termomecânico da PA6 pura, do HIPS e das blendas PP/HIPS, em função da concentração de SEBS-MA.

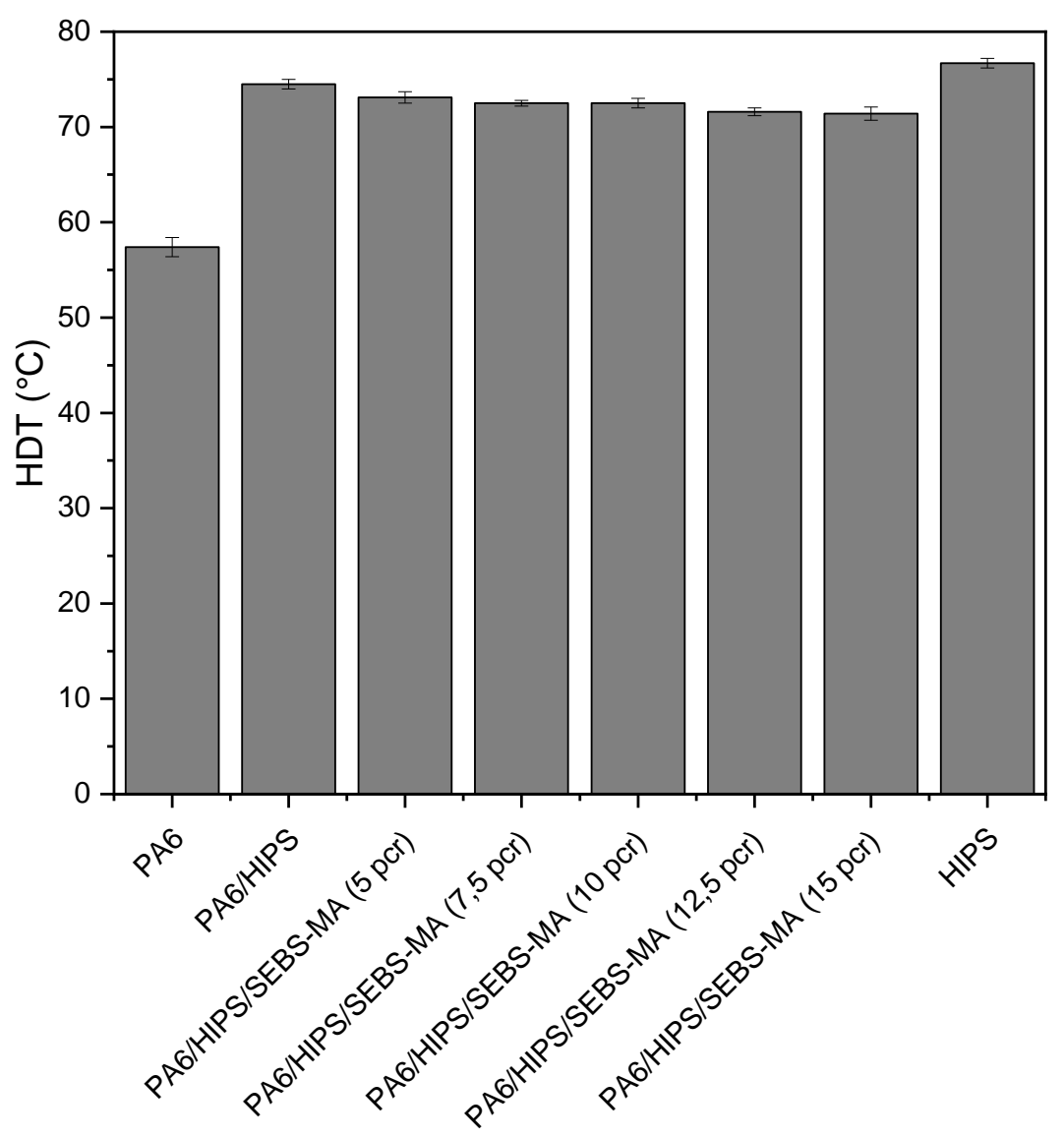

Fonte: Dados da pesquisa.

A PA6 pura apresentou temperatura de deflexão térmica na ordem de $57^{\circ} \mathrm{C}$, valor próximo ao da literatura (Oliveira et al., 2017). O HIPS tem uma HDT de $76,7^{\circ} \mathrm{C}$, indicando uma maior estabilidade termomecânica. As blendas PA6/HIPS e PA6/HIPS/SEBS-MA apresentaram valores de HDT intermediários aos dos respectivos polímeros puros, devido ao efeito da aditividade. A blenda PA6/HIPS exibiu um aumento significativo de $17,1^{\circ} \mathrm{C}$ na HDT, em comparação com a matriz de PA6. Comportamento similar também foi observado por Castro et al. (2016), com o desenvolvimento de blendas PA6/ABS.

A adição do compatibilizante SEBS-MA reduziu de maneira sutil a HDT para todas as composições compatibilizadas (PA6/HIPS/SEBS-MA), em comparação com a blenda PA6/HIPS. Esse comportamento é devido a característica elastomérica do SEBS-MA, gerando perda na HDT. Porém, as blendas PA6/HIPS/SEBS-MA continuaram com alta resistência 
termomecânica, superando a HDT da PA6 pura, em aproximadamente $12^{\circ} \mathrm{C}$. Dentro da faixa de composição investigada de SEBS-MA, as blendas PA6/HIPS/SEBS-MA não apresentaram diferenças significativas entre si, pois estão dentro da margem do erro experimental.

O aumento da resistência termomecânica (HDT) da PA6 proporcionou uma contribuição tecnológica importante, uma vez que aprimorou essa propriedade de forma significativa. A incorporação do HIPS que apresenta mais alto valor de HDT, em relação à matriz de PA6, contribuiu para o correspondente aumento da estabilidade estrutural.

\section{Conclusões}

Neste trabalho, o efeito da concentração do compatibilizante SEBS-MA na reometria de torque, na resistência ao impacto, na HDT e na morfologia das blendas de PA6/HIPS foi investigado. A blenda sem compatibilizante PA6/HIPS pode ser considerada frágil, uma vez que apresentou baixa resistência ao impacto. Tal comportamento é devido à baixa interação molecular entre os componentes. O efeito do compatibilizante SEBS-MA para melhorar a interação da blenda PA6/HIPS somente foi eficaz com 15 pcr de SEBS-MA, gerando ganhos na resistência ao impacto e mantendo a HDT alta. A morfologia obtida por MEV ilustrou que 15 pcr de SEBS-MA na blenda PA6/HIPS reduziu o tamanho médio das partículas de HIPS, assim como melhorou a adesão entre as fases, resultando em um menor nível de partículas arrancadas durante o teste de impacto. No geral, a blenda PA6/HIPS + SEBS-MA $(60 / 40 \%+15$ pcr) apresentou a melhor performance entre todas as composições investigadas, sugerindo que as propriedades da PA6 podem otimizadas por meio da mistura mecânica.

\section{Agradecimentos}

O presente trabalho foi realizado com apoio da Coordenação de Aperfeiçoamento de Pessoal de Nível Superior Brasil (CAPES) - Código de Financiamento 001 e do Conselho Nacional de Desenvolvimento Científico e Tecnológico (CNPq). Ao mesmo tempo, os autores agradecem à UFCG pela infraestrutura dos laboratórios, MCTIC/CNPq e à CAPES/PNPD.

\section{Referências}

Araújo, E. M., Júnior, E. H., \& Carvalho, A. J. F. (2003a). Compatibilização de Blendas de Poliamida 6/ABS usando os Copolímeros Acrílicos Reativos MMA-GMA e MMA-MA. Parte 1: Comportamento Reológico e Propriedades Mecânicas das Blendas. Polímeros: Ciência e Tecnologia, 13(3), 205-211, 2003 .

Araújo, E. M., Júnior, E. H., \& Carvalho, A. J. F. (2003b). Morphological, mechanical and rheological properties of nylon 6/acrylonitrile-butadiene- styrene blends compatibilized with MMA/MA copolymers. Journal of Materials Science, 38(9), 3515-3520.

Araújo, E. M., Júnior, E. H., \& Carvalho, A. J. F. (2004). Compatibilização de Blendas de Poliamida 6/ABS usando os Copolímeros Acrílicos Reativos MMAGMA e MMA-MA. Parte 2: Comportamento Termomecânico e Morfológico das Blendas. Polímeros: Ciência e Tecnologia, 14(1), 22-30.

Agrawal, P., Araújo, E. M., \& Mélo, T. J. A. (2008a). Reometria de Torque, Propriedades Mecânicas e Morfologia de Blendas Compatibilizadas de PA6/PEAD. Polímeros: Ciência e Tecnologia, 18(2), 152-157.

Agrawal, P., Araújo, E. M., \& Mélo, T. J. A. (2008). Effect of the processing method on the mechanical properties and morphology of compatibilized PA6/LDPE blends. Journal of Materials Science, 43(6), 4443-4449.

Agrawal, P., Rodrigues, A. W. B., Araújo, E. M., \& Mélo, T. J. A. (2010). Influence of reactive compatibilizers on the rheometrical and mechanical properties of PA6/LDPE and PA6/HDPE blends. Journal of Materials Science, 45(2), 496-502.

Agrawal, P., Rodrigues, A. W. B., Araújo, E. M., \& Mélo, T. J. A. (2009). Blendas de PA6/PE: avaliação da reatividade de diferentes compatibilizantes com a PA6 por reometria de torque. Revista Eletrônica de Materiais e Processos, 4(3), 1-10.

Bassani, A., Pessan, L. A., \& Júnior, E. H. (2002). Propriedades Mecânicas de Blendas de Nylon-6/ Acrilonitrila-EPDM-Estireno (AES) Compatibilizadas com Copolímero Acrílico Reativo (MMA-MA). Polímeros: Ciência e Tecnologia, 12(2), 102-108.

Bassani, A., Pessan, L. A., \& Júnior, E. H. (2005). Evolução da Morfologia de Fases de Blendas PA6/AES em Extrusora de Dupla Rosca e Moldagem por Injeção. Polímeros: Ciência e Tecnologia, 15(3), 176-185. 
Barra, G. M. O., Roeder, J., Soldi, V., Pires, A. T. N., \& Agnelli, J. A. M. (2003). Blendas de Poliamida 6/Elastômero: Propriedades e Influência da Adição de Agente Compatibilizante. Polímeros: Ciência e Tecnologia, 13(2), 94-101.

Bezerra, E. B., França, D. C., Morais, D. D. S., Ferreira, E. S. B., Araújo, E. M., \& Wellen, R. M. R. (2017). Comportamento reológico do Bio-PE e do PCL na presença do PEgAA e PEgMA. Matéria (Rio J.), 22 (1), e11798.

Bezerra, E. B., Leite, A. M. D., Araújo, E. M., \& Mélo, T. J. A. (2014). Obtenção e Caracterização de Membranas Obtidas a Partir de Blendas Poliméricas de Poliamida 6. Polímeros, 24(3), 381-387.

Bo, J., Feipeng, C., Xianzhong, Q., Bo, W., Guilin, J., \& Jinhua, G. (2021). The influence of extrusion process on micromorphology of PA 6/POE/POE-g-MA ternary blends: A quantitative analysis. Journal of Elastomers \& Plastics, 53(2), 110-122.

Castro, L. D. C., Oliveira, A. D., Kersch, M., Altstadt, V., \& Pessan, L. A. (2016). Effects of mixing protocol on morphology and properties of PA6/ABS blends compatibilized with MMA-MA. Journal of Applied Polymer Science, 133(27), 1-8.

Carvalho, A. P. A., \& Sirqueira, A. S. (2016). Effect of compatibilization in situ on PA/SEBS blends. Polímeros, 26(2), 123-128.

Chiang, C. R., \& Chang, F. C. (1997). Polymer blends of polyamide-6 (PA6) and poly(phenylene oxide) (PPO) compatibilized by styrene-maleic anhydride (SMA) copolymer. Polymer, 38(19) 4807-4817.

Correa, C. A., Yamakawa, R. S., Razzino, C. A., \& Júnior, E. H. (2007). Tenacidade à Fratura de Blendas PA 6/ABS Avaliada através do Método EWF (Trabalho Essencial de Fratura) - Parte A: Avaliação do Efeito do Compatibilizante. Polímeros: Ciência e Tecnologia, 17(1), 36-45.

Esmizadeh, E., Vahidifar, A., Shojaie, S., Naderi, G., Kalaei, M. R., \& Mekonnen, T. H. (2021). Tailoring the properties of PA6 into high-performance thermoplastic elastomer: Simultaneous reinforcement and impact property modification. Materials Today Communications, $26(3), 102027$.

Filho, E. A. S., Luna, C. B. B., Siqueira, D. D., Araújo, E. M., \& Wellen, R. M. R. (2020). Efeito do recozimento nas propriedades mecânicas, térmicas e termomecânicas da PCL. Research, Society and Development, 9(12), e13191210764.

Huang, C. H., Tan, Y. L., Guo, Z. X., \& Yu, J. (2018). Reducing water sorption of injection-molded polyamide 6 bars by polymerization-induced diffusion of styrene and grafting with polystyrene. Journal of Applied Polymer Science, 135(18), 46243.

Idumah, C. I. (2021). Recent advancements in self-healing polymers, polymer blends, and nanocomposites. Polymers and Polymer Composites. 29(4), 246258.

Lima, J. C. C., Araújo, J. P., Agrawal, P., \& Mélo, T. J. A. (2016). Efeito do teor do copolímero SEBS no comportamento reológico da blenda PLA/SEBS. Revista Eletrônica de Materiais e Processos, 11(1), 10-17.

Luna, C. B. B., Silva, D. F., \& Araújo, E. M. (2015). Estudo do comportamento de blendas de poliamida 6/resíduo de borracha da indústria de calçados. Revista Univap, 20(36), 98-110.

Luna, C. B. B., Silva, D. F., \& Araújo, E. M. (2014). Análise do comportamento termomecânico, térmico e mecânico de blendas de PA6/resíduos de borracha. Revista de Engenharia e Tecnologia, 6(1), 160-169.

Luna, C. B. B., Silva, D. F., Araújo, E. M., Melo, \& T. J. A., Oliveira, A. D. (2015b). Estudo do comportamento mecânico, termomecânico e morfológico de misturas de poliestireno/composto de borracha reciclada (SBR). Matéria (Rio de Janeiro), 20(2), 322-334.

Luna, C. B. B., Siqueira, D. D., Ferreira, E. S. B., Araújo, E. M., \& Wellen, R. M. R. (2020a). Reactive compatibilization as a proper tool to improve PA6 toughness. Materials Research Express, 6(12), 125367.

Luna, C. B. B., Araújo, E. M., Siqueira, D. D., Morais, D. D. S., Filho, E. A. S., \& Fook, M. V. L. (2020b). Incorporation of a recycled rubber compound from the shoe industry in polystyrene: Effect of SBS compatibilizer contente. Journal of Elastomers \& Plastics, 52(1), 3-28.

Luna, C. B. B., Siqueira, D. D., Ferreira, E. S. B., Silva, W. A., Nogueira, J. A. S., \& Araújo, E. M. (2020c). From Disposal to Technological Potential: Reuse of Polypropylene Waste from Industrial Containers as a Polystyrene Impact Modifier. Sustainability, 12(13), 5272.

Luna, C. B. B., Ferreira, E. S. B., Siqueira, D. D., Silva, W. A., Araújo, E. M., \& Wellen, R. M. R. (2019a). Tailoring performance of PP/HIPS/SEBS through blending design. Materials Research Express, 6(11), 115321.

Luna, C. B. B., Silva, D. F., Araújo, E. M., Mélo, T. J. A., Bezerra, E. O. T., Siqueira, D. D., \& Oliveira, A. D. (2019b). Blends of polystyrene/shoes waste (SBRr): influence of mixture sequence and compatibilizer. Macromolecular Symposia, 383(1), 1800046.

Luna, C. B. B., Ferreira, E. S. B., Silva, L. J. M. D., Silva, W. A., Araújo, E. M., Melo, \& J. B. C. A. (2019c). Blends with technological potential of copolymer polypropylene with polypropylene from post-consumer industrial containers. Materials Research Express, 6(12), 125319.

Luna, C. B. B., Siqueira, D. D., Ferreira, E. S. B., Araújo, E. M., \& Wellen, R. M. R. (2021). Reactive processing of PA6/EPDM-MA blends as modifier for application and development of high-performance polypropylene. https://doi.org/10.1002/vnl.21846.

Mello, F.B., Nachtigall, S.M.B., Salles, C.D.A., \& Amico, S.C. (2018). Compatibilization and mechanical properties of compression-molded polypropylene/high-impact polystyrene blends. Progress in Rubber, Plastics and Recycling Technology, 34(3), 117-127.

Oliveira, A. D., Larocca, N. M., \& Pessan, L. A. (2011). Efeito da Sequência de Mistura nas Propriedades de Blendas PA6/ABS Compatibilizadas com o Copolímero SMA. Polímeros, 21(1), 27-33.

Oliveira, A. D., Castro, L. D. C., Beatrice, C. A. G., Lucas, A. A., \& Pessan, L. A. (2017). Effect of Maleic Anhydride Content in Properties of PA6/AES Blends Compatibilized with MMA-MA. Materials Research, 20(6), 1630-1637. 
Research, Society and Development, v. 10, n. 8, e58510817649, 2021

(CC BY 4.0) | ISSN 2525-3409 | DOI: http://dx.doi.org/10.33448/rsd-v10i8.17649

Ren, J., Wang, H., Jian, L., Zhang, J., \& Yang, S. (2008). Morphological, thermal and mechanical properties of compatibilized nylon 6/ABS blends. Journal of Macromolecular Sciencew, Part B: Physics, 47(4), 712-722.

Rusayyis, M. A. B., Schiraldi, D., \& Maia, J. (2018). Property/morphology relationships in SEBS- compatibilized HDPE/poly (phenylene ether) blends. Macromolecules, 51 (16), 6513-6523.

Silva, D. F., Luna, C. B. B., Silva, G., Araújo, E. M., \& Mélo, T. J. A. (2014). Avaliação das propriedades mecânicas de blendas de poliestireno/composto de borracha reciclada (SBRr). Revista Eletrônica de Materiais e Processos, 9(2), 92-97.

Sundararaj, U., \& Macosko, C. (1995). Drop breakup and coalescence in polymer blends: the effects of concentration and compatibilization. Macromolecules, 28(8), 2647-2657.

Tan, Y. L, Huang, C. H., Guo, Z. X., \& Yu, J. (2018). Morphology and Mechanical Properties of Polyamide 6/Polystyrene Blends Prepared by Diffusion and Subsequent Polymerization of Styrene in Polyamide 6 Pellets. Materials, 11(5), 776.

Wang, C., Su, J. X., Li, J., Yang, H., Zhang, Q., Du, Z. R., \& Fu, Q. (2006). Phase morphology and toughening mechanism of polyamide 6/EPDM-g-MA blends obtained via dynamic packing injection molding. Polymer, 47(9), 3197-3206.

Wang, Y., Zhang, Y., Xu, Y., Liu, X., \& Guo, W. (2021). Research on compatibility and surface of high impact bio-based polyamide. High Performance Polymers. https://doi.org/10.1177/09540083211005511.

Wei, Z., Wang, R., Zhang, C., Wang, J., Yang, Y., Wang, W., \& Cao, Y. (2021). Preparation and characterization of super-toughened PA6/r-PVB blends with "transplanted" multicore morphology by reactive compatibilization. European Polymer Journal, 143(1), 110173.

Wilkinson, A. N., Laugel, L., Clemens, M. L., Harding, V. N., \& Marin, M. (1999). Phase structure in polypropylene/PA6/SEBS blends. Polymer, 40(17), 4971-4975.

Xu, M., Lu, J., Qiao, Y., Wei, L., Liu, T., Lee, P. C., Zhao, L., \& Park, C. B. (2020). Toughening mechanism of long chain branched polyamide 6. Materials \& Design, 196(11), 109173. 